\title{
Relational Activism: Reimagining WOMEN'S ENVIRONMENTAL WORK AS Cultural Change ${ }^{1}$
}

\author{
Sara O'Shaughnessy \\ EMILY HUdDART KENNEDY ${ }^{2}$
}

\begin{abstract}
We introduce the term "relational activism" to call attention to the way that relationship-building work contributes to conventional activism and constitutes activism in and of itself. In so doing, we revisit Mohai's paradox - a long-standing "ironic contrast" that notes that women's environmental concern is not reflected in greater contributions to activism than men's. We position relational activism as comprising an overlooked and underrecognized dimension of traditionally defined "activism" and highlight its role in bridging the private and public spheres. Relational activism differs from conventional activism in its location, recognition, and temporal scale. To support these claims, we draw upon 26 ethnographic interviews conducted with families who strive to reduce their environmental impact.
\end{abstract}

Key Words: gender, activism, environment, maternal politics

Résumé : Nous présentons le terme « activisme relationnel » pour attirer l'attention sur la façon dont le travail d'établissement de relations contribue à l'activisme conventionnel et constitue de l'activisme en soi. Ce faisant, nous réexaminons le paradoxe de Mohai, un « contraste ironique » déjà ancien qui souligne que la préoccupation des femmes sur l'environnement ne se traduit pas par des contributions à l'activisme plus importantes que celles des hommes. Nous situons l'activisme relationnel comme comportant une dimension négligée et peu reconnue de l'« activisme » tel qu'il est traditionnellement défini et soulignons son rôle de pont entre les sphères privée et publique. L'activisme relationnel diffère de l'activisme conventionnel pour ce qui est de l'emplacement, de la re-

1. Acknowledgements: The authors wish to acknowledge funding support from the SSHRC Doctoral Fellowships program and Strategic Environmental Grants Program. We would also like to thank Dr. John Parkins and three anonymous reviewers for their valuable comments.

2. We have adopted a convention in which the first listed author is the one who provided the majority of the theoretical framework. However, the structure and content of the paper was shared equally by the authors. Therefore, we prefer to refer to our roles as joint authors rather than as lead, or corresponding author, and second author.

(C) Canadian Journal of Sociology/Cahiers canadiens de sociologie 35(4) 2010 
connaissance qu'on lui accorde et de son échelle temporelle. Pour justifier cela, nous nous servons de 26 entrevues ethnographiques menées auprès de familles qui s'efforcent de réduire leur impact environnemental.

Mots clés: genre; activisme; environnement; politique maternelle

\section{INTRODUCTION}

From "hysterical housewives" labels (Seager 1996) to "Love Your Mother" bumper stickers (Roach 1991), gender is inescapable in the discussion of environmental activism in the Western world. Rachel Carson's Silent Spring and images of "housewife activists" like Lois Gibbs (Bantjes and Trussler 1999:180) were emblems of environmentalism from the 1960s through to the 1980s. Today, former US Vice President Al Gore and Canadian biologist David Suzuki are among the figureheads of the environmental movement. Indeed, the effect of gender on environmental attitudes and behaviours is a major area of investigation for environmental sociologists, and has resulted in rather contradictory empirical findings: although women are more likely to demonstrate higher concern for environmental issues, they are less likely to engage in environmental activism (e.g., Mohai 1992; Tindall et al. 2003). To make sense of this apparent contradiction, numerous strategies have been undertaken, including analytically separating proenvironmental activism from proenvironmental behaviours that are incorporated into daily routines. Activism, within this body of literature, is presented as a public sphere activity - a realm traditionally dominated by men.

The conceptualization of environmental activism as a public sphere activity undertaken by ecologically minded individuals, however, does not explain women's lower rates of activism. ${ }^{3}$ Moreover, it obfuscates much of the behind-the-scenes, private sphere, and community-building work performed primarily by women that makes environmental activism possible. In this article, we revisit the way in which environmental activism is typically measured, and introduce the concept of "relational activism" to better capture women's experiences with environmental activism. This term draws attention to the importance of community, networks, and communication in contributing to long-term change. Relational activism is a form of activism precisely because of the intentionality of such behaviours: these are (often) private-sphere actions undertaken with the intent of demonstrating, encouraging, or communicating

3. We use Tindall et al.'s (2003) definition of activism here: specific movement supporting activities acknowledged to be important by environmental organizations. Traditionally this includes behaviours such as attending protests, signing petitions, taking membership in an environmental group, among others. 
to others the tractability and importance of a behavioural commitment to the environment.

We argue that the traditional view of activism as a set of publicsphere activities is incomplete: there are myriad efforts behind the scenes that also constitute environmental activism. In contrast with traditional public-sphere activism, as measured in most environmental sociological work (e.g., attending protests, writing to politicians or newspapers, donating money for environmental causes, see Barkan 2004; Séguin et al. 1998; Tindall et al. 2003), relational activism is a long-term form of activism that utilizes relationships among networks of like-minded individuals, and blurs the distinction between public and private-spheres by using daily behaviours as the locus for social and environmental change. However, relational activism is not antithetical to conventional activism in its predominant conceptualization. We argue that relational activism provides important social and community support that facilitates the types of public-sphere environmental actions typically measured, while also contributing to long-term cultural change. In this way, relational activism provides important insight into the contradictory findings of environmentally conscious women's participation in environmental activism.

\section{Rethinking Activism}

Extant literature on gender differences in environmental activism and behaviours rarely provides explicit definitions of environmental activism. Most definitions have coalesced around distinctions between environmental activism and proenvironmental behaviours. For instance, Tindall et al. (2003:910) define activism as "specific movement-supporting activities that are promoted by environmental organizations" and environmentally friendly behaviour as "everyday behavior that aims to conserve the environment in various ways." Séguin et al. (1998:631) add a dimension of hierarchy to their differentiation of activism from behaviours, stating,

[e]nvironmental activists are people who intentionally engage in the most difficult ecological behaviors. They are usually members of environmental groups, are involved in fund raising campaigns or the signing of petitions, write letters to government and to policy makers, and also try to influence people's attitudes and behaviours toward the environment.

Séguin et al. further suggest that activists are distinct from nonactivists because of their commitment, hard work, autonomy, and "perception of the importance of possible problems in their local environment" 
(1998:646). Hunter et al. (2004) use environmental group membership, signing petitions, and participation in protests and/or demonstrations as examples of "activist" behaviour. Many of these activities represent an urgent and short-term reaction to environmental crises that threaten the status quo. We refer to this as "conventional activism" throughout this text.

The notion of environmental activism as an individual endeavour is troublesome from a feminist standpoint. Nearly all studies of gender differences in environmental activism and behaviours measure individual actions, although many of these actions may be taken up as a household or community decision, which may alter how people perceive their participation. For instance, a Canadian study found that nearly one-quarter of respondents identified lack of support from household members as an important constraint on their environmental behaviour (Kennedy et al. 2009). As the authors state, "In some cases the majority or the more powerful member of the household may assert his or her position in such a way that others feel they have no choice but to subvert their own priorities for the environment" (2009:154).

The most significant limitation in current conceptualizations of environmental activism and behaviour, however, is the explicit delineation of these activities along a public sphere/private sphere division. The notion that public sphere activities are more likely to be influential, difficult, and effective undergirds a tacit ranking of activism above proenvironmental behaviours (e.g., Séguin et al. 1998). Similarly, there is a perception that environmentally friendly behaviours are more easily incorporated into regular routines and therefore are "easier" to undertake, but ultimately less influential.

Recently, evidence has emerged to challenge Séguin et al.'s (1998) assertions. Little et al. (2009) demonstrated that activities such as consuming local organic food substantially increase time and energy spent on domestic tasks. A recent study by Judkins and Presser (2008) found that in middle-class, heterosexual, North American families, adopting eco-friendly household behaviours increased gendered inequalities in the division of labour, as women in their study were significantly more likely to take on the additional responsibilities entailed by a sustainable lifestyle. Dietz et al. (2009a) found that near-term household behaviours can result in reductions in household greenhouse gas emissions of $20 \%$ and reductions of 7.4\% for US national emissions. Other feminist scholars have noted that private, domestic spaces like kitchens, schools, and churches are important sites of information sharing and social mobilization for women, and can be highly influential (Murphy 1995; Reed 2000; 2003; Ruddick 1990). The work of building relationships, performed 
primarily (though not exclusively) by women, is often undertaken in the private sphere, yet may be fundamental to enabling themselves and others to participate in the public sphere. When women do enter into more traditionally "public" arenas for activist purposes, it frequently involves the transference of skills and relationships developed in the private sphere, which Ruddick refers to as "maternal politics" (1990). This relationship-building work is often overlooked in accounts of gender differences in environmental activism.

As defined by the Merriam Webster online dictionary, activism is "a doctrine or practice that emphasizes direct vigorous action especially in support of or opposition to one side of a controversial issue." There are two features of this definition we wish to amplify: that activism necessarily involves "direct vigorous action" and that activism is controversial. First, the subset of activities commonly identified as "activism" (i.e., attending protests, public action campaigns) relies on an overlooked and underrecognized set of activist behaviours that are not "direct action"; we call these relational activism. In this sense, relational activism comprises "the acts behind activism." Second, there is an implicit characterization of activism as existing in the public sphere, rather than the private sphere (Lubell 2002). We argue that relational activism intentionally uses the private sphere in a public way, contributing to mid- and longterm change. In addition to these points of clarification, we compare conventional activism and relational activism according to ontological views of the individual as an active agent and the relationship between activism and daily practices. We chose the term "relational" to describe these activist activities because of the way the actors explicitly reject the notion of an autonomous individual in relation to environmental change, and instead locate their sense of agency in their ability to engage with others to create new understandings of their proenvironmental behaviour as activism.

The idea that relationships have greater agency than individual actors also finds resonance in existing work on transformative politics, transformative activism, and social movement scholarship. Authors in these fields point to the importance of common values among individuals, and of the value of negotiation and compromise among networks, as a key part of a social movement (Diani 1992; 2000; Kriesberg 1992; McAdam and Paulsen 1993; Mische 2003; Passy 2003; Scott 2001). Diani, for instance, describes the social movement dynamic as a

process whereby several different actors, be they individuals, informal groups and/or organisations, come to elaborate, through either joint action and/or communication, a shared definition of themselves as being on the same side in a social conflict. By doing so, they provide meaning to other- 
wise unconnected protest events or symbolic antagonistic practices, and make explicit the emergence of specific conflicts and issues. (1992:2-3)

Echoing Diani, Rootes (1999:2) places networks at the centre of his definition of environmental movements, though de-emphasizing the centrality of conflict: "environmental movements are conceived as broad networks of people and organisations engaged in collective action in the pursuit of environmental benefits."

Bourdieu's (1976) work on the habitus, as well as Haluza-DeLay (2008) and others' (Smith 2003) commentaries on ecological habitus, contribute to our understanding of how daily practices, lifestyle, and relationship building can contribute to cultural change towards sustainability. It is precisely because the women interviewed acknowledged this potential that we believe relational activism should be recognized as a necessary component of activism. Rather than identify their sense of agency in their identity as individuals, the informants stressed that their actions were dependent upon - and made more effective through - a network of like-minded individuals in their community. It is the relations that result in change, rather than the actions of any one individual. This idea has been alluded to elsewhere, notably in literature on collective action, transformative politics, and social movements. While the role of relationships is central to the study and practice of collective action, Lubell (2002:432) adds, "Although political economists have long recognized the public good nature of environmental activism, models of individual behavior developed in environmental studies rarely address the logic of collective action." Indeed, many findings on activism rely on survey data that measure individual activist efforts (e.g., Barkan 2004; Séguin et al. 1998; Tindall et al. 2003).

In contrast with conventional activism, which typically encompasses activities outside the daily routine, relational activism is rooted in, and sees the potential for, social change in daily practices. For Bourdieu, daily practices are produced by the habitus. More explicitly, habitus is "the product of history, produces individual and collective practices" (Bourdieu 1976:82). Haluza-DeLay (2008) and others (Smith 2003) have commented on the potential for environmental social movement organizations to serve as a social space that influences the habitus in order to extend the adoption of environmentally supportive behaviours. As Haluza-DeLay (2008:205) writes,

In a Bourdieusian approach, environmental social movement organizations become the social space in which a logic of practice consistent with movement goals can be 'caught' through the informal or incidental learning that occurs as a result of participation with social movement organizations. 
The success or failure of such organizations to influence individual practices is dependent upon the ecological habitus: "an orientation which privileges ecological considerations" (Haluza-DeLay 2008:206). Relational activists implicitly acknowledge the existence of the ecological habitus, the environmental significance of daily practices, and consequently use this as the foundation for their activist activities, focused largely on creating relationships and networks to shift cultural norms towards sustainability.

Passy (2003) asserts that there is still a need for understanding the broad array of functions social networks play within social movements, how these functions are differentiated across individuals within these movements, and the varied meaning they hold for participants. Indeed, along with race and ethnicity (see Polletta 2005), gender is widely acknowledged as an underrepresented axis of analysis within social movements literature (McAdam 1992; Robnett 1997; Taylor 1999). Robnett's (1997) work on women's participation within the civil rights movement in the US revealed that many of the women who were excluded from formal leadership positions acted as informal "bridge leaders," building the important emotional ties that helped the wider community to be active in the movement. However, the materiality of the daily practices that build and sustain relationships and networks have not been widely emphasized within either environmental sociology or social movement literatures. Mary Mellor (2009) and numerous other feminists have insisted that scholars recognize the social reproductive labour within the household - feeding, cleaning, carework - that physically enables what is considered "productive" labour. In a parallel fashion, the material dimension of social networks and relationships that enables other members of their households and communities to take part in the more visible, publicsphere activism needs to be recognized to better understand gendered experiences of social movements.

\section{Gender Differences in Environmental Activism}

In addition to income levels (Duroy 2008; Jones and Dunlap 1992), age (Buttel 1979; Mohai and Twight 1987), and education level (e.g., Kalof et al. 1999; Jones and Dunlap 1992; Rokicka 2002; Zelezny et al. 2000), gender is one of the sociodemographic characteristics most often examined to explain differences with respect to environmental beliefs, values, attitudes, and behaviours. Zelezny et al. (2000) noted that between 1988 and 1998, over 32 articles had been published looking at gender differences in environmentalism. Yet, studies on the effects of gender continue to elude a cohesive explanation, and more often than not, result in paradoxical findings. 
Though inconsistent, empirical evidence supports the assertion that women - particularly mothers - are more likely to display values and concern for the environment (Blocker and Eckberg 1997; Stern and Dietz 1994; Zelzeny et al. 2000). However, this greater concern has not always translated into more quantifiable environmental action; a number of studies show that men are more likely to engage in environmental behaviours than women, despite demonstrating fewer environmental values and concerns (McStay and Dunlap 1983; Mitchell 1979; Mohai 1992; Tindall et al. 2003). Mohai refers to this curious finding that continues to befuddle environmental sociologists as "an ironic contrast" (1992:1), which poses a major gap in environmental scholarship. Mohai's study shows that socialization theories and structural barriers to political participation in general do not account for the discrepancies in women's environmental beliefs and actions.

Mohai's work parallels findings within wider social movement scholarship of women's comparable smaller rates of movement participation, such as McAdam's (1992) finding that women who were sympathetic to the Freedom Summer campaign (a massive voter registration campaign, which was part of the civil rights movement) in the United States were ultimately more likely than men to refrain from or quit their activist participation. While McAdam's study suggests that widespread sexual discrimination and harassment explain this discrepancy, there is little empirical evidence suggesting that these are factors in current day, North American, environmental activism. An important insight from McAdam is the observation that gender-based discrimination resulted in the reproduction of traditional gender roles within the movement along a public sphere/private sphere divide (e.g., women were often relegated to cooking for the male "activists" who participated in the voter registration campaign).

Multiple studies revisiting what has become known as "Mohai's paradox" have tried to shed light on this gendered discrepancy between the rates of activism of environmentally conscious women and men. These include a study of attitudes toward forest certification programs (Ozanne et al. 1999), a comparison of male and female members of environmental organizations (Tindall et al. 2003), and a national survey of public and private environmental behaviours (Hunter et al. 2004). Ozanne et al. (1999) conclude that had Mohai "used another criterion for proenvironmental behavior, such as personal action in the market place, rather than environmental organization membership, the paradox would have been resolved" (1999:620). Tindall et al. (2003) clarify the findings by Ozanne et al. (1999) by distinguishing between "activism" and "environmentally friendly behaviour." They compare consistent participa- 
tion in behaviours that are easily incorporated into daily routines, such as "taking public transit, recycling, or using a reusable mug" (2003:913). Like Mohai (1992), Tindall et al.'s (2003) study concludes that women do have greater concern for the environment which manifests in daily environmentally friendly behaviours, rather than formal activism. Finally, Hunter et al. (2004) argue that a distinction between "public" (e.g., volunteering with an environmental organization) and "private" (e.g., recycling) proenvironment behaviours can provide much needed insight into Mohai's paradox. The authors find no statistically significant differences in public behaviour between men and women, and find that men are more likely to engage in private behaviours than public ones, and at a lesser rate than women (Hunter et al. 2004).

However, caring for or about the environment is not simply a personal moral disposition. As Macgregor asserts, caring as a disposition should be conceptually distinguished from "caring as a set of material practices (i.e., to take care of something or someone as a form of labor)" (2004:58). The assumption that both forms of care are inherently connected informed much early ecofeminist scholarship, which led to claims that women are intrinsically closer to nature and likely to care about environmental issues. Yet, as Macgregor (2004) and others have argued, women's participation in environmental activism is a highly variegated phenomenon, with many women taking part in highly politicized activities within environmental social movements (e.g., Sandilands 1999), and other women actively protesting in opposition to environment activists (e.g., Reed 2000).

While previous studies, whether by environmental sociologists or ecofeminists, have generally suggested that women are more environmentally concerned and likelier to adopt environmentally friendly behaviours than men, the key issue within Mohai's paradox — that women who display environmentally conscious attitudes are less likely to participate in environmental organizations and activism - has not, in fact, been resolved. By reconsidering and refining our existing notions of activism, as well as the (false) dichotomy between public and private sphere, we acknowledge the myriad ways in which women themselves understand and identify with environmental activism. To do so we build on extant literature to construct the concept of relational activism, using excerpts from interviews conducted between June 2009 and November 2009.

\section{Methods}

The data for this paper are drawn from the qualitative portion of a mixedmethod research project undertaken, by one of the authors, as part of a 
doctoral thesis. The broader research project involves exploratory interviews with 13 families who are actively trying to reduce their material consumption. The thrust of the interviews was to identify the practices involved in reducing consumption, the barriers to and supports for such sustainable behaviours, and the ways reducing consumption can enhance quality of life. As qualitative research, the sample is purposively and theoretically driven. The seed sample included three families, known to the research team through acquaintances, and identified as living lowimpact lifestyles. Subsequent sampling followed the snowball method and was theoretically driven. For example, research questions relating to the importance of context led the researcher to locate informant families in both suburban and urban neighbourhoods. Each of the 13 families was interviewed twice; interviews were conducted with three couples, two fathers, and eight mothers. Informants have between two and five children living at home.

Although not strictly ethnographic (as the study did not involve participant observation), the interviews conducted followed ethnographic principles. By this we mean that interviews were semistructured and unstructured (semistructured for the first, unstructured for the follow-up), the interview guides were designed to elicit information about subcultures of individuals who consciously strive to reduce their consumption, the information obtained from respondents was often material (i.e., regarding daily practices, networks of support), and during data analysis, there was a conscious effort to identify motivating values. The interviews lasted between 45-90 minutes and were conducted between June 2009 and November 2009. Analysis was conducted using NVivo 8, a qualitative data organization software and followed ethnographic data analysis procedures, as described by Spradley (1979). The overall purpose of the analysis was to identify and describe the unique features of the identified subculture (those who voluntarily and significantly reduce consumption), locate the relationships among these unique features, and note how those relationships contribute to the configuration of the subculture as a whole. Each interview was transcribed verbatim, then read and coded by the primary researcher. After all interviews were coded once, the primary researcher organized the resulting themes and coded the 26 interviews a second time.

\section{Results}

We use excerpts from the interviews to describe relational activism and compare it to conventional activism. The results are split into the following subsections: relational activism, relational activism for household 
sustainability, and the relational activism behind conventional activism. Many of these themes are overlapping, however, and the results should be read in their entirety rather than as distinct sections.

\section{Relational Activism}

Relational activism is behind-the-scenes work. Women practicing relational activism rarely make the headlines yet their work creates social change and they are, for the most part, aware of this. By living lives that are distinct from the mainstream, they stand out in their neighbourhoods - again, this is a conscious choice. They use the relationships they have formed in their communities as catalysts for environmental change. By choosing to be conspicuously different from what social norms would dictate, these families are quietly leading a vanguard of cultural change towards sustainability.

The first excerpt from Jamie, ${ }^{4}$ a mother of two, alludes to relational activism as a broad-based form of change that involves commitment to changing one's lifestyle and the belief that this is an important part of a general shift towards sustainability. Here Jamie is responding to the question of whether individual environmental action is sufficient to address environmental problems.

I am under no illusion that my individual actions will stop global warming, but I think the opinion that individual actions are insignificant is kind of a male perspective, that everything is sort of separate. What our family is doing is demonstrating a lifestyle that is more consistent with how people should live.

Jamie is tacitly reacting to the assumption that public and private spheres are separate and that we can create no change through personal actions. Jamie has always chosen to demonstrate her commitment in this way while other informants recounted a shift towards this relational work, consciously distinguishing between activism and relational activism. It is not only that relational activism builds on relationships, but that the pressure point for change is often in the emphasis on building diverse networks of support for environmental behaviour. A good example of this is Leslie, a mother of two, who tells how she demonstrates her commitment to the environment. Leslie and her family do not own a car, deliberately choose to live in a small home, and frequently volunteer at the farmers' market and other environmentally focused events. She says,

I went through a long phase of calling myself an environmental activist, and I recently moved back from doing that sort of work. I guess I found

4. Pseudonyms are used to protect the identities of informants and individuals mentioned by informants. 
it more valuable, instead of being with people who already agreed with me about what the problems were, to stay in my diverse community and live the best way that I could. If you are living well and are relatively happy and healthy, people will wonder why you are that way and might be inspired by that.

Leslie is deliberately placing private-sphere activities in the public sphere, for purposes of social change. Relational, like conventional activism, seeks to effect change in the face of specific environmental issues. Uniquely, relational activism has a specific and local audience. As Leslie stressed, her audience is diverse, they live in her neighbourhood, and they do not necessarily have the same principles or behaviours as Leslie and her family. Relational activists know their audience: by virtue of the fact that such relationships exist, private sphere behaviours can come to the public sphere and influence others to, in turn, change their own private actions.

Relational activism fits within a neighbourhood context. Rather than conventional activism, which is often out of sync with daily schedules and demands, relational activism requires a longer term investment of time, but can be incorporated into daily practices. Here, an informant describes how her family contributes to sustainability in an unconventional way.

It turns out that our family can give a lot here and we get a lot back, just by doing what brings us joy. My husband loves bicycles and he can be ...on the front porch and the neighbors come by and say, 'Oh can you help me with this?' And we also do free bike repairs once a year. In this way we ... get more people to ride. If we help them fix their bicycles they'll ride more.

Relational activists strive to form relationships in their communities with the goal of reducing barriers to sustainable behaviour. In particular, there is an emphasis on quotidian behaviours (relating back to the ecological habitus). Repairing bikes is not conventional activism but as intentional behaviour used to get more people out of their cars and on their bikes, and to build relationships in one's local community, this form of relational activism can have environmentally and socially significant consequences.

\section{Relational Activism for Household Sustainability}

The household is considered to be part of the private sphere, suggesting that there is little opportunity for effecting change in the polis. Yet, just as television advertisements and telecommuting are allowing the public sphere to infiltrate private households, many relational activists are re- 
fashioning the boundaries of these spheres to make households a space for information sharing and social change. In other words, relational activists can use lifestyles as a part of their activism. For example, below, Jane, mother of two, describes a canning workshop she hosted in her home:

I was the canning expert amongst the others. It started when [a group of women in the neighbourhood] started talking about how many tomatoes were ripening ... we ended up having dinner together afterwards and it was really fun.

This seemingly simple example would not typically be considered "activism." However, Jane had a deliberate goal of making it easier for others to lessen the environmental impact of daily practices (eating) and used her home as the platform for this action.

Relational activism often uses the home as a "show-home of sustainability." These families are helping to shift norms away from heavily consumptive patterns of living by showing how low-consumptive choices can be attractive and pleasurable. The home is used as a site to lead by example - a key component of relational activism. Importantly, there is recognition that people pay attention to how others' homes are furnished and that there lies an opportunity for change in this social truth. Below, Karen, a mother of five, describes explicitly the opportunity for change inherent in visibly demonstrating — rather than advocating - one's daily practices, and practicing what one preaches.

I realized you can have all the opinions in the world you want but it's not going to change anyone else's mind. You have to lead by example. That's really influential in terms of the way I do things. I am conscious of the fact that I am modeling for others.

Karen is aware that she has the ability to change others' daily practices through visibly modeling her own. She later said that after becoming more political in her involvement with local foods, she is now recognized by people she does not know. She stresses that for her this means she has an even greater capacity to affect change.

\section{The Relational Activism behind Conventional Activism}

Central to the definition of relational activism is that this is behind-thescenes work that is nearly always called upon in conventional activism involving more than one person (e.g., a protest rather than writing to a newspaper). More explicitly, we argue that when women form networks of individuals who can be called upon to engage in conventional activ- 
ism, the very act of forming and maintaining a network constitutes relational activism. Below we use interview excerpts to describe the importance of "the acts behind activism."

We asked Karen - who is active in community organizing — what she considered an effective way to encourage individuals to adopt environmental practices into their daily lives. She emphasized the need for a relational approach, clearly stating her opinion that this is a more effective - and less common - way to promote change.

I think first of all, [change] needs to be relational. So rather than writing to your MP, going to your MP's office will make a much more significant impact.... The relational model starts with sitting down and talking to people about what their hopes are, what their pressures are and gradually you can sort of tease out common stories and then it's about telling our stories. So then you can begin to build community, which is a rare thing these days, we have lots of institutions but we don't have a lot of community.

Later, Karen expands on this, highlighting the relationships between relational activism and conventional activism (in this case, protesting City Council's proposed legislature on development):

If you're going to make change on the grand scale, I do think you have to eventually get to a point of actually working with other people because I mean, one person is one person.... And it really is true that it doesn't take a lot of people if the relationships and the passion are strong and they're committed. But they do have to be connected and they do have to have a common vision.... And once someone is able to sit down with a group of other people and discover that they share similar pressures and they share similar hopes, they then begin to see themselves as change makers and they'll go and meet with their councilors and they'll call up their friends and say, 'Come out to City Council.' And that's how you get five hundred people in council chambers - by actually building those relationships.

As demonstrated in the above quotation, participation in conventional activism was not absent from the households of the women interviewed. In many cases, women's relationship-building skills and willingness to take on high levels of community responsibilities facilitated the participation of other members of their households and communities to take part in conventional activism.

We use the quotations below to posit "maternal politics" as a form of relational activism. Maternal politics makes use of women's roles as caretakers and transfers this role to the political sphere (Murphy 1995; Ruddick 1990). We argue that maternal politics is a form of relational activism. Through their relationships, women can lobby for and help to create the change they want to see for their children's (and others') 
future. Below, Jane describes how she seeks to make political change through her friendship with a local politician. These excerpts call attention to one of the myriad ways in which women use intimate relationships not only to communicate ideas and encourage proenvironmental behaviours, but also to enact change at a political level.

I told Eva to talk to the preeminent solar guy in Edmonton who's got all kinds of ideas about what needs to be done. She set up a meeting with him and now she's an expert on all of those things. Just little things like that have made a difference. So I've been telling her lately, 'You know local food is a really important issue. I hear them talking about it in the city but you're never talking about it in the province so whenever you get a chance you should be talking about local food.'

Not all contributions to a political campaign are quantifiable, visible, or acknowledged. Below, we provide another example of one mother babysitting the children of a successful campaigner for political office. This act of relational activism is actually nested amongst the effects of previous acts of relational activism. Mothers wanting to create a social, public space for their children to play volunteered to form a playgroup. Building on these relationships, this woman explains how her connections to the political campaign grew out of her involvement with the playgroup.

[After the successful campaign] there was a big victory party, and we were home with [the politician's] kids... Actually, there are a lot of people that we met through that very first baby group who also were involved in [the campaign]. So you would go into the volunteer office [for the campaign] and there would be five or six people that you knew anyway and so that's kind of cool.

We have used the interviews to more explicitly define the concept of relational activism, showing how this unique form of activism is related to environmental sustainability and how it supports conventional activism. We argue that conventional activism is only one part of activism, and that the overlooked component could be described as relational activism. For example, we show how conventional activism relies heavily on daily practices structured around the household in order to be successful, even when these practices are not themselves typically considered "activist" behaviours. We also show that in bringing the private sphere to the public, these daily, materialist practices can come to comprise an ecological habitus. Finally, we show that conventional activism also relies on the intentional relationship-building work designed to create networks of support for conventional environmental activism. 


\section{Discussion}

We advance the concept of relational activism as a form of activism that is overlooked and underrecognized. In contrast with conventional activism, we suggest relational activism as a long-term form of activism. However, relational activism is not antithetical to conventional activism in its predominant conceptualization. Rather, relational activism provides important social and community support that facilitates public-sphere environmental actions and contributes to long-term cultural change. Relational activism provides important insight into the contradictory findings of women's participation in environmental activism. As our results demonstrate, using women's experiences and perspectives to widen the scope of what is considered environmental activism helps to shed light on Mohai's paradox. Eco-conscious women in our study are not, by their own accounts, less likely to take active steps to protect the environment and influence the behaviours and beliefs of others. Rather, they are actively and consciously choosing the form of activism - in this case relational activism - that aligns most closely to their environmental values and allows them to maximize their impacts. In summary, there are three key distinctions between conventional activism and relational activism: relational activism conceives of the individual as a member of a community; relational activism uses daily practices to change norms of high consumption; and third, relational activism uses the private sphere for public purposes.

Relational activism locates agency in the collective, and uses relationships as the locus for change. Describing maternal politics, Abrahams (1996:791) explains, "women's community participation, not necessarily tied to social movements, constitutes an often overlooked location where collective identities emerge." Most importantly, relational activism is not individuals acting atomistically to save the environment: they see themselves as acting as a collective, and are therefore potentially more accountable to, and have more influence upon, each other. There is some doubt as to the efficacy of households in constructing a sustainable society (Monbiot 2007). Indeed, individuals acting alone will likely have little impact if they are not affecting and affected by others. This is where relational activism becomes extremely relevant: the mothers interviewed here are demonstrating ways that sustainable living can be tractable, pleasurable, and meaningful - both socially and environmentally. They are shifting cultural norms away from high-consumptive lives and towards "rich lives, instead of lives of riches" (Leiserowitz and Fernandez 2008:78). The household is the site of many of our daily activities. When outsiders enter and leave our homes, informants argued, there is the po- 
tential for these guests to be made aware of practices of which they were previously unaware. They may act as "pollinators," shifting norms slowly so that practices like using a rain barrel, canning food, and living without a car can come to be considered as commonplace as recycling and using cloth bags. Social norms strongly shape household daily practices (Poortinga et al. 2004), thus demonstrating ways that low-impact living can fit within a household's existing practices with no adverse effects on well-being, which represents a potentially powerful force of change (Dietz et al. 2009b). Recycling and using cloth bags are now fairly widespread. For illustrative purposes, we speculate that perhaps homes that were early adopters of recycling and using cloth bags, and intentionally made these choices public by using their networks of family, friends, and acquaintances, played a role in bringing such practices into the sphere of normality. We would describe such individuals as "relational activists."

Haluza-DeLay (2008:213) argues that,

[a]n alternative logic of practice — that of ecologically sound lives — will need to be creative and explicit, since it appears illogical to the dominant social field's existing logics. In their efforts to rename the social reality, insurgent social movements must develop this reflexive analysis.

To do so, he argues, the environmental movement needs to communicate specific information on environmentally sustainable living, critique the social structures that inhibit such lifestyles, and finally, demonstrate how the social field resists "the codes and internalization of an environmental praxis" (2008:214). The informants in this study provide examples of environmentally sustainable lifestyles through their show-homes of sustainability, and make this display more than identity formation (Douglas and Isherwood 1979; McCracken 1986) and status depiction (de Botton 2004; Veblen 1994 [1899]). They do so by locating their sense of agency as part of a group, rather than as autonomous agents. We see conventional activism as an effective means by which to accomplish HaluzaDeLay's second point: critiquing inhibitive social structures.

Our study challenges the ranking of environmental conventional activism over environmental behaviours posited by Séguin et al. (1998), who suggested conventional activism requires more commitment and is ultimately more effective. The informants in our study articulate their transition to relational activism as a conscious choice to become more committed and involved with environmental change. In fact, a number of informants cited disenchantment with the results of conventional activism, such as letter writing and partaking in protests. We should note that there are some limitations with the data presented here. Given the small number of people interviewed, we do not seek to generalize our find- 
ings to the population level. Rather, it is our hope that this exploratory research will, to a certain extent, reorient environmental sociologists in particular to consider the more feminine work of relationship building. When relationships are forged and maintained as part of one's commitment to facilitate a shift to sustainability, we argue, this relational work should be considered to constitute activism.

We do not discuss power and politics in this paper. This is not to say that these are not relevant to the topic, in fact both likely play a large role in determining the success or failure of relational activism. Conducting interviews in urban and suburban areas brought to the foreground the effect that structure has on daily practices. In the central area, where there was a critical mass of like-minded individuals, a supportive Member of Parliament and Member of the Legislative Assembly, informants felt empowered to influence others in their neighbourhood. By contrast, residents of the suburban area felt overwhelmed by the influx of big-box retail and culture of consumption. One participant even moved over the course of this project, because she had concerns about raising her schoolage children in a culture of excess. In brief, relational activism draws on the potential for greater agency among networks of individuals with common values (as opposed to individuals acting alone). However, there are still structural barriers that limit the extent to which such networks can form and influence households, policy, and neighbourhood structure.

\section{Conclusion}

We argue that there is a feature of activism that is missing from current accounts of activism - and that this is a gendered feature. Relating to the concept of ecological habitus and the construction of meaning within social relationships, we use the term relational activism to describe a set of activities that we believe are of primary importance to the environmental movement (and other social movements not discussed here). The relational work that takes place largely unseen and unrecognized plays a role in mitigating environmental crises and bettering our ability to respond. As climate change exacerbates existing environmental challenges such as drought, flooding, fire, and loss of biodiversity, societies need strong communities that can react effectively. We believe that relational activism is needed to ensure resilient and sustainable communities exist - as well as to sustain conventional activism. Specifically, we point to the "acts behind conventional activism," showing how some women who are strongly concerned with the environment express this concern by using their household as a "show-home for sustainability," by supporting others' endeavours in conventional activism, and by fostering a 
long-term cultural shift towards low-impact living. While relational activism is not limited to women, this study speaks to the methodological importance of starting from different standpoints to enrich our understandings of environmental activism.

\section{REFERENCES}

Abrahams, Naomi. 1996. Negotiating power, identity, family, and community: Women's community participation. Gender \& Society 10(6):768-796.

Bantjes, Rod and Tanya Trussler. 1999. Feminism and the grass roots: Women and environmentalism in Nova Scotia, 1980-1983. Canadian Review of Sociology \& Anthropology 36(2):179-197.

Barkan, Steven E. 2004. Explaining public support for the environmental movement: A civic voluntarism model. Social Science Quarterly 85(4):913937.

Blocker, T. Jean and Douglas Lee Eckberg. 1997. Gender and environmentalism: Results from the 1993 General Social Survey. Social Science Quarterly 78(4):841-858.

Bourdieu, Pierre. 1976. Outline of a Theory of Practice. Cambridge and New York: Cambridge University Press.

Buttel, Frederick H. 1979. Age and environmental concern: A multivariate analysis. Youth \& Society 10(3):237-256.

De Botton, Alain. 2004. Status Anxiety. New York: Penguin Books.

Diani, Mario. 1992. The concept of social movements. The Sociological Review 40(1):1-25.

2000. Simmel to Rokkan and beyond: Towards a network theory of (new) social movements. European Journal of Social Theory 3(4):387-406.

Dietz, Thomas, Gerald T. Gardner, Jonathan Gilligan, Paul C. Stern, and Michael P. Vandenbergh. 2009a. Household actions can provide a behavioral wedge to rapidly reduce US carbon emissions. Proceedings of the National Academy of Sciences. 106(44):18452-18456.

Dietz, Thomas, Eugene A. Rosa, and Richard York. 2009b. Environmentally efficient well-being: Rethinking sustainability as the relationship between human well-being and environmental impacts. Human Ecology Review 16(1):114-123.

Douglas, Mary and Baron Isherwood. 1979. The World of Goods. New York: Basic Books.

Duroy, Quentin M.H. 2008. Testing the affluence hypothesis: A cross-cultural analysis of the determinants of environmental action. Social Science Journal 45(3):419-429.

Haluza-DeLay, Randolph B. 2008. A theory of practice for social movements: Environmentalism and ecological habitus. Mobilization 13(2):205-218. 
Hunter, Lori M., Alison Hatch, and Aaron Johnson. 2004. Cross-national gender variation in environmental behaviors. Social Science Quarterly 85(3):677-694.

Jones, Robert Emmet and Riley E. Dunlap. 1992. The social bases of environmental concern: Have they changed over time? Rural Sociology 57(1):28-47.

Judkins, Brooke and Lois Presser. 2008. Division of eco-friendly household labor and the marital relationship. Journal of Social and Personal Relationships 25(6):923-941.

Kalof, Linda, Thomas Dietz, Paul C. Stern, and Gregory A. Guagnano. 1999. Social psychological influences on vegetarian beliefs. Rural Sociology 64(3):500-511.

Kennedy, Emily Huddart, Thomas M Beckley, Bonita L. McFarlane and Solange Nadeau. 2009. Why we don't "walk the talk": understanding the environmental values/behaviour gap in Canada. Human Ecology Review 16(2):151-160.

Kriesberg, Louis. 1992. International Conflict Resolution. New Haven, CT: Yale University Press.

Leiserowitz, Anthony A. and Lisa O. Fernandez. 2008. Toward a new consciousness: Values to sustain human and natural communities. Environment: Science and Policy for Sustainable Development 50(5):62-29.

Little, Jo, Brian Ilbery, and David Watts. 2009. Gender, consumption and the relocalisation of food: A research agenda. Sociologia Ruralis 49(3):201217.

Lubell, Mark. 2002. Environmental activism as collective action. Environment and Behavior 34:431-454.

Macgregor, Sherilyn. 2004. From care to citizenship: Calling ecofeminism back to politics. Ethics and the Environment 7(1-2):85-96.

McAdam, Doug. 1992. Gender as a mediator of the activist experience: The case of Freedom Summer. The American Journal of Sociology 97(5):12111240 .

McAdam, Doug and Ronnell Paulsen. 1993. Specifying the relationship between social ties and activism. The American Journal of Sociology 99(3):640 667.

McCracken, Grant. 1986. Culture and consumption: A theoretical account of the structure and movement of the cultural meaning of consumer goods. Journal of Consumer Research 13(1):71-84.

McStay, Jan R. and Riley E. Dunlap. 1983. Male-female differences in concern for environmental quality. International Journal of Women's Studies 6(4):291-301. 
Mellor, Mary. 2009. Ecofeminist political economy and the politics of money. Pp. 251-267 in Ariel Salleh, ed., Eco-Sufficiency \& Global Justice: Women Write Political Ecology. London: Pluto Press.

Mische, Ann. 2003. Cross-talk in movements: Reconceiving the culture-network link. Pp. 258-280 in Mario Diani and Doug McAdam, eds., Social Movements and Networks: Relational Approaches to Collective Action. New York: Oxford University Press.

Mitchell, Robert C. 1979. Silent springs/solid majorities. Public Opinion 2(1):16-22.

Mohai, Paul. 1992. Men, women, and the environment: An examination of the gender gap in environmental concern and activism. Society and Natural Resources 5(1):1-19.

Mohai, Paul and Ben W. Twight. 1987. Age and environmentalism: An elaboration of the Buttel model using national survey evidence. Social Science Quarterly 68(4):798-815.

Monbiot, George. 2007. Heat: How to Stop the Planet from Burning. Toronto: Random House Canada.

Murphy, Kathleen. 1995. Women's political strategies in a logging town. Pp. 164-184 in Lawrence F. Felt and Peter R. Sinclair, eds., Living on the Edge: The Great Northern Peninsula of Newfoundland. St John's: Institute of Social and Economic Research.

Ozanne, Lucie K., Craig R. Humphrey, and Paul M. Smith. 1999. Gender, environmentalism, and interest in forest certification: Mohai's paradox revisited. Society and Natural Resources 12(6):613-622.

Passy, Florence. 2003. Social networks matter. But how? Pp. 21-48 in Mario Diani and Doug McAdam, eds., Social Movements and Networks: Relational Approaches to Collective Action. New York: Oxford University Press.

Polletta, Francesca. 2005. How participatory democracy became white: Culture and organizational choice. Mobilization 10(2):271-288.

Poortinga, Wouter, Linda Steg, and Charles Vlek. 2004. Values, environmental concern, and environmental behavior. Environment and Behavior 36(1):70-93.

Reed, Maureen G. 2000. Taking stands: A feminist perspective on 'other' women's activism in forestry communities of northern Vancouver Island. Gender, Place and Culture 7(4):363-387.

2003. Marginality and gender at work in forestry communities of British Columbia, Canada. Journal of Rural Studies 19(3):373-389.

Roach, Catherine. 1991. Loving your mother: On the woman-nature relation. Hypatia 6(1):46-59.

Robnett, Belinda. 1997. How Long? How Long? African-American Women in the Struggle for Civil Rights. New York: Oxford University Press. 
Rokicka, Ewa. 2002. Attitudes toward natural environment: A study of local community dwellers. International Journal of Sociology 32(3):78-90.

Rootes, Christopher. 1999. Environmental movements: From the local to the global. Environmental Politics 8(1):1-12.

Ruddick, Sara. 1990. Maternal Thinking: Toward a Politics of Peace. New York: Ballantine Books.

Sandilands, Catriona. 1999. The Good-Natured Feminist: Ecofeminism and the Quest for Democracy. Minneapolis: University of Minnesota Press.

Scott, R.W. 2001. Institutions and Organisations. London: Sage Publications.

Seager, Joni. 1996. Hysterical housewives and other mad women. Pp. 271-283 in Dianne Rocheleau, Barbara Thomas-Slayter, and Ester Wangari, eds., Feminist Political Ecology. London: Routledge.

Séguin, Chantal, Luc G. Pelletier and John Hunsley. 1998. Toward a model of environmental activism. Environment and Behavior 30(5):628-652.

Smith, Edwin. 2003. Ethos, habitus and situation for learning: An ecology. British Journal of Sociology of Education, 24(4):463-470.

Spradley, James P. 1979. The Ethnographic Interview. New York: Holt, Rinehart and Winston.

Stern, Paul C. and Thomas Dietz. 1994. The value basis of environmental concern. Journal of Social Issues 50(3):65-80.

Taylor, Verta. 1999. Gender and social movements: Gender processes in women's self-help movements. Gender \& Society 13(1):8-33.

Tindall, D.B., Scott Davies, and Céline Mauboulès. 2003. Activism and conservation behavior in an environmental movement: The contradictory effects of gender. Society and Natural Resources 16(10):909-932.

Veblen, Thorstein. (1994) [1899] (in English). The Theory of the Leisure Class. New York: Penguin Books.

Zelezny, Lynnette C., Poh-Pheng Chua, and Christina Aldrich. 2000. Elaborating on gender differences in environmentalism. Journal of Social Sciences 56(3):443-457.

Sara O'Shaughnessy is a Ph.D. candidate in the Department of Rural Economy at the University of Alberta. Her research interests include intersections of gender and natural resource development, and feminist methodology.

Emily Huddart Kennedy is a Ph.D. Candidate in the Department of Rural Economy at the University of Alberta. Her previous research has focused on environmental values and the gap between intentions and actions with respect to environmental behaviour. Currently, her research interests are in sustainable consumption, mixed methodology, and ecological citizenship. 